\title{
Introduction to Harold Garfinkel's Ethnomethodological "Misreading" of Aron Gurwitsch on the Phenomenal Field
}

\author{
Clemens Eisenmann ${ }^{1}$ (D) $\cdot$ Michael Lynch ${ }^{2,3}$
}

Accepted: 15 October 2020 / Published online: 19 April 2021

(C) The Author(s) 2020

\begin{abstract}
This article is the editors' introduction to the transcript of a lecture that Harold Garfinkel delivered to a seminar in 1993. Garfinkel extensively discusses the relevance of Aron Gurwitsch's phenomenological treatment of Gestalt theory for ethnomethodology. Garfinkel uses the term "misreading" to signal a respecification of Gurwitsch's phenomenological investigations, and particularly his conceptions of contextures, functional significations, and phenomenal fields, so that they become compatible with detailed observations and descriptions of social actions and interactions performed in situ. Garfinkel begins with Gurwitsch's demonstrations with line drawings and other abstract examples, and suggests how they can be used to suggest original procedures for investigating the vicissitudes of embodied practical actions in the lifeworld. This introduction to the lecture aims to provide some background on the scope of Gurwitsch's phenomenological critique and elaboration of Gestalt theory and Garfinkel's "misreading” of it in terms of his own conceptions of indexicality and accountability, and ethnomethodological investigations of the production of social order.
\end{abstract}

Keywords Ethnomethodology and conversation analysis · Phenomenology · Embodied action · Gestalt theory · Sociology of perception · Practice theory · Aron Gurwitsch · Harold Garfinkel

Clemens Eisenmann

Clemens.Eisenmann@uni-siegen.de

Michael Lynch

MEL27@cornell.edu

1 Collaborative Research Centre 1187: Media of Cooperation, University of Siegen, Siegen, Germany

2 Department of Science \& Technology Studies, Cornell University, 306 Morrill Hall, Ithaca, NY 14850, USA

3 School of Media and Information, University of Siegen, Siegen, Germany 


\section{Introduction}

\section{“'Making the phenomenon available' again."}

During the 1992-1993 academic year, Harold Garfinkel (1917-2011) offered a graduate seminar (Sociology 271) on Ethnomethodology in the Sociology Department at the University of California, Los Angeles, a course he gave in different forms over many years. The 1992-1993 version of the seminar covered a number of topics that Garfinkel was developing at the time: instructed actions, tutorial problems (including exercises with inverting lenses), and ethnomethodological studies of work. Many of these topics are covered in publications that came out during the final decade of his life (Garfinkel 2002, 2007a, b), but one topic that was given extensive coverage in the seminar series has not been covered at much length in Garfinkel's published works to date: Aron Gurwitsch's treatment of Gestalt theory, and particularly the themes of "phenomenal field" and "praxeological description". In one of the seminars (26 April 1993), Garfinkel lectured at length on Gurwitsch, and we have edited the transcript of that seminar for publication in this journal. ${ }^{1}$ The present article is our introduction to it.

In the lecture, Garfinkel rather briefly discusses the background of Gurwitsch's arguments within philosophy and gestalt psychology, and focuses instead on what he calls an "ethnomethodological misreading" of selections from Gurwitsch's writings. As his lecture makes clear, this "misreading" is not offered as an incorrect way to read Gurwitsch, nor as a disrespectful appropriation; instead, it is offered as a creative transposition or "respecification" (Garfinkel 1991) that finds in Gurwitsch's writings inspiration and suggestiveness for a kind of research very different from what Gurwitsch might have recognized or countenanced. Garfinkel neither claims to recover what Gurwitsch originally intended nor to disrespect the value of Gurwitsch's writings. Although a thorough discussion would exceed the limits of this brief introduction, we believe it would be helpful to provide some background on the scope of Gurwitsch's treatment of Gestalt theory and Garfinkel's "misreading" of it.

\footnotetext{
${ }^{1}$ Transcripts and audio tapes of the seminars are available in the Garfinkel archive in Newburyport, MA. (See Acknowledgements). We edited the transcript-there was no indication of the transcriber's name, but whoever it was did a commendable job-to correct some typographical errors, and to make out names or terms that the transcriber wrote with phonetic spellings. We further checked the transcript with the digital record of the tape, filled some gaps and added colloquial details. Whenever possible, we endeavored to supply citations and references for authors and publications that Garfinkel mentions or alludes to in the transcript. We also deleted portions of the seminar that dealt with 'housecleaning issues,' such as managing the scheduling and discussing student assignments. As he did in many of his seminars, Garfinkel took up much of the time by presenting a continuous lecture, but there also were occasional student interventions and dialogues. Our editing preserved the lecture, along with selected dialogues that were tied to the contents and contributed to the continuity of the lecture.
} 


\section{Gurwitsch and Garfinkel}

Aron Gurwitsch (1901-1973) was a phenomenological philosopher who incorporated Gestalt theory into his philosophical studies of perception and consciousness. Originally born in Vilna, Lithuania to a line of Jewish scholars, his family moved repeatedly in his early life to escape pogroms in Eastern Europe. He pursued higher education in Germany, where he developed his interests in Gestalt psychology, phenomenology, and the sociology of knowledge, and made contact with leading figures such as Max Wertheimer and Edmund Husserl. With the rise of the Nazis in 1933, he and his wife fled to Paris, where he taught for several years at the Sorbonne in a special unit for emigrant scholars. During his years in Paris he met with Alfred Schutz for the first time, and Maurice Merleau-Ponty attended his lectures. In 1940, with the fall of France, Gurwitsch emigrated once again, eventually settling in Cambridge, Massachusetts, where he held temporary positions at Harvard University, Wheaton College and eventually Brandeis University, teaching mathematics, physics, and philosophy. He later moved to the New School of Social Research in New York, succeeding the recently-deceased Alfred Schutz, with whom he had become friends after both had settled in the US to escape Nazi persecution (Grathoff 1989: xix-xxii).

During the late 1940s and early 1950s, when Garfinkel was completing his PhD under Talcott Parsons' supervision at Harvard, he attempted to integrate phenomenology with Parsonian theory to develop an original conception of social action. He met frequently with Gurwitsch, between 1946 and 1951 at Gurwitsch's house in Cambridge, and later acknowledged that Gurwitsch was his main tutor in phenomenology. In 1957 Garfinkel, Aaron Cicourel and Egon Bittner hired a graduate student (Arturo Biblarz) to translate Gurwitsch's The Field of Consciousness, which enabled Garfinkel to read it several years before the English translation was published (1964). ${ }^{2}$ According to Garfinkel:

That [translation] gave both of us early textual access in English to Gurwitsch's argument on the functional significations and their coherence of figural contexture in its empirical perceptual details. That argument has been a foundational point of departure in all my teaching. It has lasted a long time. It has also been missed as Ethnomethodology's key resource in identifying Ethnomethodology's concerns to specify 'the problem of meaning' [...]. (Garfinkel 2002: 84)

\footnotetext{
${ }^{2}$ The Field of Consciousness (1964) was first published in French: Théorie du champ de la conscience (1957). According to Gurwitsch (1964: vii) the manuscript for the book was finished in its final form in 1953. However, "on October 9, 1950, Aron Gurwitsch wrote to his friend Alfred Schutz that, except for some minor revisions and corrections of the English, The Field of Consciousness was finished and would soon go to the translator and publisher in France. [...] The delays involved were remarkable, even for that time, and the thinking behind what was published in 1957 and 1964 goes back [...] to Gurwitsch's studies in Germany during the 1920s and his teaching in Paris during the 1930" (Embree in Gurwitsch 2010: 413). Rawls (in Garfinkel 2002: 167, Fn. 26) mentions that during the time he was meeting Garfinkel in Cambridge, Gurwitsch was "writing his book for a second time. He lost the first manuscript when he fled from France to Morocco to escape the Nazis".
} 
Garfinkel frequently discussed Gurwitsch during his seminars at UCLA, but his published writings provide only brief references to Gurwitsch. For example, in Studies in Ethnomethodology (1967), he mentions Gurwitsch only once, in the preface, in contrast to abundant references to Schutz. He mentions Gurwitsch several times in Ethnomethodology's Program (2002), and includes an account of what he means by an ethnomethodological "misreading" of Gurwitsch (2003: 177, 258), but these mentions are brief and compressed; couched in phrases such as "Gurwitschian contextures of organization* details" and "Gurwitsch's autochthonous gestalt phenomena," which are not explicated or given much background (see also Garfinkel and Livingston 2003). Garfinkel (2007b) offers some of its background regarding the phenomenal properties in navigation, briefly touching upon Gurwitsch's example of how two points comprise a "contexture" of phenomenal properties as a "pair" (2007b: 27). There is some further elaboration on his relationship to Gurwitsch in ethnomethodological scholarship and biographies of Garfinkel, such as Wieder (1974: 188ff.); Heritage (1984: 37f.); Lynch (1993); Maynard (1996); Rawls (2002); Psathas (2004); Watson (2008); Eberle (2012); Liberman (2013); and Vom Lehn (2014), but, again, these elaborations tend to be brief. Fele (2008) provides a more elaborate account of what Garfinkel draws from Gurwitsch and other phenomenologists, and Meyer (forthcoming) also goes into more depth about his relationship to Gurwitsch and mentions the 1993 seminar that we are introducing here. During that seminar, on 26 April 1993, Garfinkel gives what is perhaps his most extensive, indepth treatment of Gurwitsch's phenomenology of perception, and shows why he recommended that "for the serious initiatives of ethnomethodological investigations [...] Gurwitsch is a theorist we can't do without".

\section{Misreading Gurwitsch}

In preparation for Garfinkel's 1993 seminar, students had been asked to read the chapter "Some principles of Gestalt Psychology," in The Field of Consciousness by Gurwitsch (1964: 85-153). Early in his lecture, Garfinkel refers to the first section of the chapter on "The Constancy Hypothesis and Its Abandonment". 3

The prior summer (1992), Garfinkel had entered into an agreement with Anne W. Rawls to publish a new collection of his studies to mark the 25 year anniversary of the publication of Studies in Ethnomethodology, and he was beginning to select materials for the new collection-which eventually was published a decade later (Garfinkel 2002). Although we have been unable to locate all of the tapes, or transcripts of the other lectures for the 1993 seminar series, there are similar transcribed lectures and seminars from this time period, which are available in the Harold

\footnotetext{
3 In addition to the selections from Gurwitsch, readings for the seminar series also included publications, or draft copies of later-published articles, by Garfinkel (1963); Garfinkel et al. (1981); Garfinkel and Sacks (1970); Garfinkel and Wieder (1992); Livingston (1987); Bjelic and Lynch (1992); Lynch (1991a); Macbeth (2012); Benson and Hughes (1991); as well as a chapter from Merleau-Ponty (1962: 52-63) on "the phenomenal field".
} 
Garfinkel Archive in Newburyport. ${ }^{4}$ Garfinkel deemed these lectures important and sorted them into different folders for various publication projects, only some of which were used for Ethnomethodology's Program. In these lectures, references to the importance of Gurwitsch are especially frequent, and he emphasizes their pertinence to topics in ethnomethodology. As Garfinkel put it in preliminary comments for his seminar the previous year:

The Gurwitsch thing will come up as a kind of a ghost in the house. Make yourself acquainted at least, with the text. I'm not asking that you master the text. Make yourself acquainted with the section in there where in fact he's talking about the functional significations. The book itself, I think, is a masterpiece. Those of you who want great things in your library, you should buy it. You'll need to be careful that you don't get distracted. (Transcript of Garfinkel seminar, SOC 271, “Tutorial Problems," 20 April 1992, p. 61)

In an overview of the reading assignments for the seminar in the following year (1994), Garfinkel emphasizes the central relevance of Gurwitsch's findings for Ethnomethodology, but he also recommends to the students that they should "misread" The Field of Consciousness (1964) in order to extend Gurwitsch's phenomenological insights and investigations of "paper and pencil drawings" to the lived-phenomena, the vicissitudes of practical actions and practical circumstances, that ethnomethodology investigates:

It's not that Gurwitsch is to be criticized. It's that ethno[methodology] must deliberately and carefully misread Gurwitsch, with which to find what the ethno is after: [...] It's that these achievements are lived work. That's what we're after. And for that, then, it has to be asked, well what does the coherence of objects consist of, just in any actual case? [...] By misreading, I understand that you read, or misread, or read again, or read differently than Gurwitsch can be meaning, because there's something more that you're reading it for, you're reading it for what you need of him, in order to teach the brilliance of his criticism of Gestalt theory. (Garfinkel lecture, " $1{ }^{\text {st }}$ meeting: Readers I and II and Preview of Lectures," SOC 218B, 11 January 1995, p. 10f.).

He makes a similar recommendation for "misreading" Merleau-Ponty's (1962) "demonic" discussion of "phenomenal field".

Garfinkel's ethnomethodological misreading consists of treating the phenomenal field as a praxeological achievement that cannot be investigated solely through the phenomenological study of the perception of figures or of a series of notes that make up a melody or chord, as per Gurwitsch's approach, but in embodied practical actions in the lived social world. In other words, it is a matter of taking Gurwitsch's treatment of the line drawings made famous in Gestalt theory (the famous diagrams of alternating figures and optical illusions that demonstrate perceptual continuities

\footnotetext{
4 The archive contains a massive collection of materials which continue to be sorted and digitized in collaboration with the Collaborative Research Centre "Media of Cooperation" at the School of Media and Information at the University of Siegen, Germany.
} 
and contextures), as guidance for detailed, concrete observations of organizationally achieved social objects. Gurwitsch addresses the organization of perception as an autochthonous achievement, inherent to the stream of individual consciousness. Garfinkel extends this into the social world of enacted practices, in what Anderson and Sharrock (2018: 4) have dubbed "third-person phenomenology".

Garfinkel asks, on the one hand, how the coherence of the phenomenal field and its properties and details-i.e., the sensual fields opened up in and through embodied, oriented actions - are produced and accomplished in everyday practices. On the other hand, Garfinkel addresses the witnessable, describable, and instructable production of that field. The crux, and contingency, of the matter is that these two questions cannot be separated, because praxeological descriptions are part and parcel of what they describe. This is the essential accountability and reflexivity of practical actions. ${ }^{5}$ And it is consequential, since Garfinkel treats the embodied and social accomplishment of coherence and its instructable description as autochthonous to action, evident and intelligible in its own right with no standing need for explanatory formulation by members or professional analysts. That is, sense and accountability are achieved in vivo, in the course of practical actions, and if clarification and repair are needed, they too are achieved as occasional matters in the course of such actions. Accordingly, accountable action is achieved without need for theoretical grounding or reductive procedure; its organization is to be found out practically and empirically. Theoretical abstractions or conceptualizations would add yet another layer of complication that thereby threatens to lose (or obscure) the phenomenon achieved in its own right.

Garfinkel develops this fundamental and rather complex argument over the course of the Gurwitsch lecture, showing how it is indebted to Gurwitsch and proposing where ethnomethodological investigations of social phenomena depart from, and go beyond, what he calls Gurwitsch's "transcendental phenomenological criticism of Gestalt theory". When given a close reading, the central argument already becomes apparent in his opening paragraph.

Garfinkel begins his lecture on Gurwitsch by announcing that he will introduce the Gurwitsch article and its "critical slogans," such as "the notion of the phenomenal field, of phenomenal detail, of the coherence of details, coherence of objects," all of which "are giving the point in their origins, are giving the material grounds for talking like that". It is noticeable that Garfinkel is speaking about "slogans"-a vernacular word that lacks the dignity of theoretical terms or analytical concepts. He also makes no reference to the secondary literature on Merleau-Ponty or Gurwitsch, but instead suggests that students should find guidance for explicating these "slogans" through their own "investigations in perspicuous settings" — - settings

\footnotetext{
5 "Ethnomethodological studies analyze everyday activities as members' methods for making those same activities visibly-rational-and-reportable-for-all-practical-purposes, i.e., 'accountable,' as organizations of commonplace everyday activities. The reflexivity of that phenomenon is a singular feature of practical actions, of practical circumstances, of common sense knowledge of social structures, and of practical sociological reasoning" (Garfinkel 1967: vii).

6 "A perspicuous setting makes available, in that it consists of, material disclosures of practices of local production and natural accountability in technical details with which to find, examine, elucidate, learn of, show, and teach the organizational object as an in vivo work site" (Garfinkel 2002: 181).
} 
produced through lived practices "with which then, those slogans take on their character as descriptions". Thus, he introduces the notion of "praxeologized descriptions," i.e., descriptions that are made readable, and use-able in an instructional sense, at "a worksite" to reveal phenomena glossed by the slogans. In this sense, Garfinkel closes the opening paragraph of the lecture with the question: "What does a phenomenon consist of as [...] an instructionably observable revealed phenomenon of practical action?" This question, however, is about the achievement of social actions in a phenomenal field and not about an explication of the theoretical meaning and significance of the concept of "phenomenal field". The so-called slogans are treated as something that has to be found out practically and empirically (their "material grounds"). Talking about a phenomenal field is-directly from the beginning-done in order to find out how phenomena (including their embodied observability and describability) are made "instructionable" and observably achieved. When this is the case, Garfinkel is no longer talking about slogans, but about praxeological descriptions: descriptions that are not something additional to and corresponding with a phenomenon and its properties (which would lose the phenomenon), but are part of the phenomenon's "instructionable" production and reproduction.

In this sense, when Garfinkel says that the notion of the phenomenal field is "giving the point in its origins" he evidently is not aiming at a theoretical explication, but at showing why and precisely how it is relevant to find a sense of what Gurwitsch or Merleau-Ponty write in reference to the empirically observable "material grounds" of a distinctive organization of actions. It is about demonstrating what their slogans - "the phenomenal field, of phenomenal detail, of the coherence of detail, of the coherence of objects"-might consist of as descriptions of some-body's (or some-bodies') local and endogenous achievements in, of, and as a phenomenal field of the very actions that achieve it. ${ }^{7}$ Therefore, early on in his seminar, Garfinkel introduces "tutorials" — such as an exercise with "inverting lenses" (Garfinkel 2002: 207-212) to disrupt the fluency of actions-which require embodied experiences with phenomenal fields ("making the phenomenon available," "making ordinary bodily tasks inspectable"), instead of merely "talking about" them. This also refers to Garfinkel's notion of "misreading": "Take Gurwitsch's findings and then administer them, meaning, they're the first segment of an instructed action, then go follow

\footnotetext{
7 Garfinkel also stressed this point in another lecture, regarding the slogan of praxeological validity: "At least ethnomethodologically, what we'd like to do, is to find perspicuous settings with which to explicate that slogan. So, we want not to be engaged in the textual exercises of explicating that proposal. But we want instead to find in perspicuous settings what that slogan consists of as the locally endogenously produced work of producing some most ordinary organizational object" (Garfinkel seminar, SOC 271, "Praxiological Validity of Instructed Action," 04 May 1992: 4). See also the following note under the headline "Caution": "Only with exercises in hand can the questions be asked: What did we do? What did we learn? In the absence of actual studies the claim encourages a literary explication of it as a text, which can open up endless distractions" (Garfinkel, List of Perspicuous Settings / List of Tutorial problems; Harold Garfinkel Archive).

8 "Tutorials do not reveal phenomenal fields with the same clarity if they are only read. Garfinkel urges the reader to actually try the exercise and believes that reading the text without doing the exercises is another way to lose the phenomenon" (Rawls 2002: 33).
} 
them". 9 The misreading thus aims at reading Gurwitsch's "descriptions as instructions the work of following which exhibits the phenomenon that the text describes" (Garfinkel 2002: 95; also see 178).

For such a reading, Garfinkel states that one also needs to know what one is looking for with these tutorials. Garfinkel partially credits Gurwitsch with the insights the "misreading" would make intelligible, but the grounding of those insights is achieved through the tutorial exercise, and not in the text or in Gurwitsch's intentions in writing it. ${ }^{10}$

In the lecture, Garfinkel highlights as "Gurwitsch's achievement" in finding that the phenomenal field-including the coherence of objects-is an endogenous (autochthonous) achievement. In this regard, Garfinkel follows and acknowledges Gurwitsch on three major points: (1) that there is no need to look for additional properties, such as a "Gestalt" or "schema" external to, and/or abstracted from, the phenomenal field; (2) that it is pointless to imagine that an organizing principle lies in the heads or minds of the individuals who would produce the coherence of the phenomenal field; and (3) that instead one should look at the details and specifics of the "display," in which the coherence is made demonstrable and observable.

Garfinkel demonstrates these points by using Gurwitsch's (1964: 106ff.) example of a series of points, or what Garfinkel calls "dots," and inscribing them on a blackboard, starting with one, and then two, and then a series of pairs of dots. The demonstration shows how a pair of dots, exhibits phenomenal field properties-that they are paired, that a line can be inscribed through them, and that one of them is a left-hand member and the other a right-hand member-which are observable and demonstrable in the contexture of details of the display. In other words, the gestalt contexture of the pair is not an additive feature when one dot is inscribed next to the other (with "next to" being part of the contexture). ${ }^{11}$ The phenomenal field properties are neither externally imposed nor 'subjectively' imagined. Instead, they are endogenously produced as properties, in, as, and of the developing details of the display. In this example, one dot by itself would not signify that it is a left-hand member of a pair of dots, which only gets exhibited "in an arrangement of appearances". Thus, the so-called "functional signification" of a "left-hand member" only becomes apparent in the "relationship of contexture," i.e., of the two dots in relation to the space between and around them.

\footnotetext{
9 Garfinkel introduces this notion of using Gurwitsch's argument as one part "of a pair" in his lecture on "Tutorial Problems": "I think you'll find in your first reader an article by Gurwitsch in which he offers the generic essential invariant features of occasional expressions. He does that with the use of the transcendental phenomenological method. What I'm proposing is that the findings then, as a result, can be used by you. You might even want to take it on as a problem, to ask, where in the world will you find any single case of what he's talking about? I'm serious. You can use his findings as the first segment of an instructed search. Use those details that he offers, and go searching to find the cases he's talking about" (Garfinkel, SOC 271, "Tutorial Problem," 20 April 1992, p. 14).

10 Gurwitsch (1964: vii) himself emphasizes a more practical approach in his preface, stating that he "wanted to make it a phenomenological study, not a book about phenomenology."

11 See Lynch (1991b) for a discussion of topical "contextures" that draws upon Gurwitsch and Garfinkel.
} 


\section{The Field of Consciousness}

The foundational problem Gurwitsch addresses can be understood as nothing less than the philosophical question of how perception is possible. Gurwitsch (1964: 5) aims to develop "a phenomenological field-theory of consciousness"12 that incorporates concepts and principles from psychology, and particularly Gestalt theory. For that endeavor, Gurwitsch asks, how is it possible that we perceive an ordered world, and how is this organization of perception achieved?

To simplify, Gurwitsch starts with a juxtaposition of David Hume's Empiricism and William James' Pragmatism. For Hume, Gurwitsch says, consciousness is comprised of various sense data and different modes of perception, "as an accumulation or succession of elements which are intrinsically unrelated to one another" (Gurwitsch 1964: 15). Gurwitsch instead follows James, who provides a contrastive account of "the continuity and streamlike nature of experience" (Gurwitsch 1964: 16). While for Hume the question is how the perceiver groups the various disconnected sensory elements, the contrary question for James, he says, is how persons actively discriminate and decompose distinct perceptions from the totality of experience. James finds this solution in the active subject whose selective agency achieves organization through directed interest and variations of attention, including shifting between the focus and margins of consciousness.

In contrast, Gurwitsch problematizes the underlying background: the presumption that sensory experience 'in itself' is unorganized and chaotic. Thus, 'something' - here the selective agency of the human subject-needs to intervene in order to establish organization and furnish ordered perception. Gurwitsch also ascribes such an underlying conception of unorganized sense data to Jean Piaget, for whom cognitive "schemata" that are learned and applied play the crucial role in organizing perceptual experience. Here schemata and concepts entail "a dualistic view of perception: sense-data are interpreted as organized by, and receiving structure from, extraneous nonperceptual factors or functions" (Gurwitsch 1964: 51).

Gurwitsch then turns towards von Ehrenfeld, Stumpf, and Husserl, among others, for whom "the mere coexistence or immediate succession of elementary data suffices to give rise to a form-quality, without any special mental activity intervening" (Gurwitsch 1964: 69). Gurwitsch criticizes how, in this conception, the ideal form-qualities or Gestalts are founded on "a sensuous quality of a higher order," and as such through an external principle. He differentiates this criticism from the foundational concepts of the "School of Graz"13 articulated in Meinong's thesis of

\footnotetext{
12 Phenomenology, following Husserl, is the framework for Gurwitsch's (1964: 5) investigations "by means of descriptive analyses of the appearances of objects through acts of consciousness." From this theoretical starting point, Gurwitsch (1964: 6) in his own way "misreads" Gestalt theory and the psychology of James: "James's great work and also some of his later writings do contain philosophical motifs and possibilities which may be evolved along phenomenological lines, even though James's own development actually followed a different course. It therefore seems legitimate to take up those motifs and possibilities and to develop them in a phenomenological manner".

13 The "School of Graz" refers to a group of experimental psychologists at the "Gratzer Institute for Psychology," that was founded by Alexius Meinong in 1894 and developed with his students Christian von Ehrenfels, Vittorio Benussi and Alois Höfler among others. Meinong argued-in opposition to the
} 
the ideality of objects of a higher order that requires a process called "production" for providing organization. Gurwitsch further discusses the notion of Verschmelzung (fusion) by Stumpf, which is also endorsed by Husserl, who actually aimed not to postulate extra-sensuous properties. However, "owing to Verschmelzung, unity is bestowed upon the sense-data concerned" (Gurwitsch 1964: 81). Thus, Gurwitsch shows how, even in this case, organization is achieved through processes extraneous to the perceptual situation.

While Gurwitsch discusses, and partially incorporates details from, these various approaches, he follows a rather different trajectory. Instead of starting with unordered sense data, or unorganized stuff of experience, which would require external or internal (learned or unconscious) non-sensory processes to become organized in perception, Gurwitsch begins with experience as already (more or less) organized; as an autochthonous achievement. As he states up front: "Organization is inherent and immanent in immediate experience, and not brought about by any special organizing principle, agency or activity" (1964: 8).

Thereby, Gurwitsch advances an argument from James about the concept of "saliency". However, phenomenal saliency for James was again to be subordinated to the selective and conceptual agency of the mind. ${ }^{14}$ For Gurwitsch, to the contrary, saliency is a decisive organizing principle that accounts for the actual achievement of perception, but not as an external principle that bestows organization on the chaos of sensation. Instead, it originates with and is exhibited in experience: "Saliency of a group of data so that this group emerges and segregates itself from the stream is a feature not introduced into the stream, but yielded by the stream itself' (1964: 31, italics in original).

Gurwitsch finds another foundational argument in the critique of the "constancy hypothesis" by the more recent era of Gestalt psychology; namely, that of Köhler, Wertheimer, and Koffka (see also Fele 2008). The constancy-hypothesis states that certain sense stimuli give rise to corresponding sensations. "In other words, the assumption is that sense-data depend exclusively and exhaustively upon external stimuli, so that the same sensations recur whenever the same stimuli act upon the receptor organs" (Gurwitsch 1964: 70). The founders of Gestalt psychology disavowed this view, and showed that a perceptual gestalt depends on the contextual

\footnotetext{
Footnote 13 (continued)

"Berlin School" - that Gestalts, although of a higher order (the superiora), are not simply given, but are founded on sense-data (the inferiora), which they subsequently modify in an extra-sensuous process of "production". The Berlin School of experimental psychology refuted such a notion of production. It was founded by Carl Stumpf (1893) whose students — mainly Kurt Koffka, Wolfgang Köhler and Max Wertheimer - Gurwitsch adopts and builds on for formulating his fundamental critique. (Kurt Lewin also was part of this group). Both, Stumpf and Meinong, were students of Franz Brentano and thus can also be viewed as belonging to the "Brentano School".

14 As James (1987: 735) states in A Pluralistic Universe: "We of course need a stable scheme of concepts, stably related with one another, to lay hold of our experiences and to co-ordinate them withal. When an experience comes with sufficient saliency to stand out, we keep the thought of it for future use, and store it in our conceptual system. What does not of itself stand out, we learn to cut out; so the system grows completer, and new reality, as it comes, gets named after and conceptually strung upon this or that element of it which we have already established."
} 
relation of each singular figure to its ground. Its parts, elements, or properties are not independent sensory data, but are constituted in experience for any given gestalt in its figure-ground-complex (see also Maynard 1996). To use a very simple example, a grey dot will be perceived differently depending on the color of its surroundings. Gurwitsch follows the Gestaltists ${ }^{15}$ and elaborates on the notion of functional significations:

It is the functional significance of any part of a Gestalt-contexture that makes this part that which it is. The part is what it is only as a constituent of the Gestalt-contexture and as integrated into its unity. Any part of a Gestalt may then be said to be determined as to its existence by its functional significance in the sense that the part only exists in, and is defined by, its functional significance. (Gurwitsch 1964: 121, italics in original)

Gurwitsch then extends his foundational critique to all of the aforementioned theories and argues that they implicitly retain adherence to the "constancy hypothesis," originating from a dualistic conception that already "appears in the very distinction between 'sensation' and 'perception"” (1964: 88). Such a dualism, Gurwitsch argues, implies that sense-data are modified by some kind of extraneous non-sensual processes. "The important point is that, according to all traditional theories, percepts are asserted to grow out of mere sense-data owing to supervenient factors (of whatever kind and description) by means of which sensations are interpreted and meaning is bestowed upon them" (1964: 88). Gurwitsch does not deny that, for organized perception, some internal and external factors, selection principles, schemata, learning and development, and habits are involved. However, he insists, following Koffka (1924), ${ }^{16}$ that these do not explain "the actual occurrence" of the "achievement of organization" itself. Gurwitsch aims to account for this achievement in terms of reorganization and reconstruction of experience itself. Thereby, "all features displayed by perception must be treated on the same footing" as what the stream of consciousness consists of.

While Garfinkel speaks about Gurwitsch's critique of Gestalt Psychology, Gurwitsch's endeavor could also be described as applying the findings of Gestalt Psychology (particularly of Köhler, Wertheimer, and Koffka; see Ellis 1938) and extending their theoretical relevance to the fields of phenomenology and psychology. Thus, by grounding his profound critique in Gestalt psychology, Gurwitsch

\footnotetext{
15 Gurwitsch (1964: 52) also grounds his notion of organization in the findings of Gestalt psychology: "By insisting upon organization and structure as exhibited by the perceptual field, Gestalt theory conforms to the phenomenal findings. In fact, the perceptual field is experienced as organized. The segregated units which emerge from the field present themselves in experience as having structure and organization in their own right."

16 In his psychology of child development Koffka (1924: 152) describes practices such as swimming or solving a picture-puzzle, which once successfully achieved significantly change the situation. He concludes: "The problem of learning, therefore, is not merely one of finding out how later performances depend upon earlier ones-which is essentially the problem of memory-but also involves the question: How does the first performance come about? Hereafter we shall refer to this as the problem of achievement". Koffka (1924: 179ff.) further elaborates this problem of first-time acquisition with regard to Köhler's experiments with Chimpanzees.
} 
addresses the description and foundations of consciousness in his further advancement of phenomenology regarding the structure of the thematic field and its relations to theme (that which is in the focus of attention) and margin (Gurwitsch 1964: 307 ff.). As a result, structural parallels to central notions of ethnomethodology become visible in Gurwitsch's (1941) "non-egological conception of consciousness," which emphasizes not the perceiving ego, but the experience of perception and relevancies that arise from the given observable details and their interdependencies. He does so by describing the order that is already provided for, as well, in his consequential and radical critique of theoretical dualisms.

\section{The Relevance of Gurwitsch's Critique of Dualistic Theories of Perception for Ethnomethodology}

Although Gurwitsch engages in 'first-person' phenomenology, his arguments can be seen as foundational for-or structurally parallel to-central conceptions in ethnomethodology concerning (1) the question of social order, (2) the role of theoretical reductions and praxeological descriptions, and (3) the notion of "indexicality". However, as we pointed out earlier, ethnomethodology deals with these issues within lived social practices. Consequently, as Garfinkel argues in the seminar, Gurwitsch's achievement "is only a tremendously powerful initiative, but doesn't take us where we want to go". 17

(1) "There is order in the plenum". ${ }^{18}$ Hobbes' question of how social order is possible is crucial for sociology, and was of major concern for Parsons. Garfinkel's treatment of what he calls "order in the plenum," holds a critical relation to social theory analogous to Gurwitsch's critique of theories and philosophies of perception, although Garfinkel transposes those to the field of constitutive, embodied social practices. Garfinkel shows how the assumption of a lack of order in the "concrete," moment-to-moment conduct of everyday affairs, leads Parsons, and most of formal analytic sociology for that matter, to the solution "that only methods of constructive analysis could provide-only and entirelyfor any and every orderliness whatsoever, for every one of the endlessly many topics of order" (Garfinkel 1988: 106). Stated in vernacular terms, it is typically assumed that ordinary language and everyday action are too "messy"-idiosyn-

\footnotetext{
17 Maynard (1996: 2) makes a similar argument, when he states: "Had social psychology followed early insights about the self-generating and indigenous grounding of gestalts, it might well have eventuated in ethnomethodology". However, he also acknowledges the specific further development by Garfinkel: "going a step beyond gestalt perception and respecifying the holistic phenomena of everyday life as something extant in the orderly concerted practices of actors in their actual, lived situations" (1996: 2).

18 Garfinkel did not explain his choice of the term "plenum"-a term often associated with physical theories of the luminescent ether that postulated space thoroughly filled with matter. The view of the plenum he attributes to Parsons is of a primordial condition that is intractable to analysis until processed through conceptual schemes and/or methodological constructs that enable analysis to get off the ground. Garfinkel (1988: 105) briefly mentions various usages of a corresponding plenum, by James, Whitehead, Husserl and others, asking: "Who has used the notion of a plenum and for what?"
} 
cratic, variable from one occasion to the next, bound up in the contingencies of the moment-to provide meaningful analytical data. To become usable as sources of social science data, it is thought that persons and their activities must first be run through experimental protocols, standardized questionnaires, and coding schemes. Garfinkel, and also Sacks (1984), rejected that view and proposed that "naturally organized ordinary activities" were produced and recognizable to members as ordered in a moment-to-moment way. From the outset, ethnomethodology aimed to demonstrate the locally produced, occasioned, contextual orderliness of action and interaction, and this resonated with Gurwitsch's critique of theories of perception that presume the primacy of unorganized sensory data and then investigate how organization is imposed upon them (see also Fele 2008: 302, Fn. 10).

(2) At a more abstract level, Gurwitsch's critique of philosophies and theories of perception targets an implicit dualism. Similarly, Garfinkel's aforementioned notion of the "plenum" not only pertains to Parsons' theories of social action and social structure, it applies to what he sometimes calls "the worldwide social science movement". ${ }^{19}$ When arguing for an autochthonous achievement, one needs to account for the coherence of phenomena and their actual achievement from within a given contexture, or in ethnomethodology, from within actual settings of social action (where 'settings' are not external to that achievement, but are bound up with the achieved contexture). Extraneous explanations are simply incapable of providing an account that is, in Garfinkel's words, "specifiably adequate". This is a crucial point that Garfinkel also highlights in his introduction to his 1994 course reader: "You reduce them, you lose the phenomenon. That's Gurwitsch's tremendously brilliant teaching" ("1st meeting: Readers I and II and Preview of Lectures," SOC 218B, 11 January 1994, p. 10). The argument resembles the aforementioned notion of praxeological descriptions. Just as the coherence of the phenomenal field is an inherent part of the stream of perception, its details irreducible in vivo, praxeological descriptions are also intrinsic to what they describe. They cannot be reduced through the intervention or imposition of analytical theorizing or phenomenological reduction, without losing the phenomena.

(3) Instead of using reduction procedures, such as frames, coding schemes, taxonomies, indices, and so forth, phenomena have to be accounted for in terms of their indexicality and the natural accountability of practical actions. In his lecture to the seminar, Garfinkel invokes the notions of reflexivity and accountability, and introduces them in connection with a discussion of praxeological descriptions (and Lebenswelt-pairs). The notion of indexicality also is relevant to Gurwitsch's concept of functional signification (see also Meyer forthcoming). In a paper he presented at ASA, Garfinkel (1965) acknowledges Gurwitsch's demonstrations for their use of "indexical particulars". In this presentation he also elaborates

\footnotetext{
19 “The result, according to Garfinkel, is 'Parsons' plenum': a world which is conceived of as essentially disorderly; a world in which order can only be discovered after, and as a result of, the application of a social scientific method" (Rawls 2002: 23).
} 
on Gurwitsch's example of the two dots, while highlighting a temporal as well as spatial contingency in the way he inscribes one dot on the board, pauses, and then comments on its prospective spatial property of left-hand member only as a consequence of inscribing the second.

In a display of a "pair of dots" the particulars "left hand member," "right hand member," and "separating interval" implicate each other as an "ensemble of mutually relevant functional characters." Because of these connections if I put a mark on the board and say to you, "Here is the lefthand-member-of-a-pair-of-dots," and I haven't drawn the rest, the function "left hand member of a pair" has the property that the particular does not signal, or cue, or indicate, or portend, or stand proxy for its consequences; but rather the particular consists of its consequences. Or rather, in the way it consists of its consequences it signals, cues, indicates, portends, lies, glosses, metaphorizes or stands proxy for its consequences (Garfinkel 1965: $7 f.)^{20}$

Similar to Gurwitsch's notion of functional significance "within the organizational contexture into which it is integrated," indexical expressions or occasioned expressions, "have a definite sense and reference according to the place in which the utterance or the expression is done" (Garfinkel 1965: 22). Its relation to sign functions also demarcates Garfinkel's approach to the problem of meaning (see Rawls and Turowetz 2019).

\section{Conclusion}

Despite these parallels, it is of major importance to recognize that and how Garfinkel departs from Gurwitsch, especially regarding the notion of ideality of meaning and transcendental analysis. Garfinkel repeatedly reminds his students of the differences between ethnomethodology and Gurwitsch's phenomenology, and he also marks differences from other sociological enterprises, specifically Goffman's.

The April 1993 seminar thus has a double-edged value. It elaborates on Garfinkel's debt to Gurwitsch, while at the same time displacing Gurwitsch's field on to a different ground. Gurwitsch's field is that of perceptual consciousness, exhibited and made analyzable through inscriptions on two-dimensional surfaces of pages and blackboards; Garfinkel's field is a field of embodied actions, in the thickness of lived space and time, populated by things, irreducibly intersubjective, infused with language, inhabited by the presence and absence of other beings. Gurwitsch's dots and line drawings nevertheless have pedagogical value for opening up Garfinkel's field, and so he doesn't simply leave Gurwitsch behind when he enters ethnomethodology's door. He holds on to the keys that Gurwitsch provides.

\footnotetext{
${ }^{20}$ Garfinkel used this demonstration for decades in his lectures and seminars, perhaps because of its extreme simplicity, and yet effectiveness for getting across basic points about Gestalt contexture and functional significations.
} 
In addition to providing an extended account of what Garfinkel makes of, and out of, Gurwitsch's Gestalt philosophy, the April 1993 seminar is rich with brief asides and digressions in which Garfinkel comments about his use of Schutz, his attitude toward publishing, his relationship with Goffman, and many other matters. Garfinkel's published writings are intimidatingly difficult for many readers. Although his lectures also deploy peculiar idioms and unique turns of phrase that can be baffling, the lecture/seminar style is less dense and places a lighter burden on the reader. We also have preserved some of the dialogues with students in which Garfinkel elaborates, explains, and otherwise makes more plainly available what he could possibly be talking about.

Acknowledgements We are grateful to Jason Turowetz for locating the seminars and their digital sound files, and to Anne W. Rawls, Garfinkel's literary executor, for permission to publish the edited transcript of the seminar as well as for their insights on the topic.

Funding Open Access funding enabled and organized by Projekt DEAL. Funded by the Deutsche Forschungsgemeinschaft (DFG, German Research Foundation)—Project-ID 262513311—SFB 1187, Collaborative Research Centre: "Media of Cooperation".

\section{Compliance with Ethical Standards}

\section{Conflicts of interest None.}

Open Access This article is licensed under a Creative Commons Attribution 4.0 International License, which permits use, sharing, adaptation, distribution and reproduction in any medium or format, as long as you give appropriate credit to the original author(s) and the source, provide a link to the Creative Commons licence, and indicate if changes were made. The images or other third party material in this article are included in the article's Creative Commons licence, unless indicated otherwise in a credit line to the material. If material is not included in the article's Creative Commons licence and your intended use is not permitted by statutory regulation or exceeds the permitted use, you will need to obtain permission directly from the copyright holder. To view a copy of this licence, visit http://creativecommons.org/licen ses/by/4.0/.

\section{References}

Anderson, R. J., \& Sharrock, W. W. (2018). Action at a distance: Studies in the practicalities of executive management. Abington: Routledge.

Benson, D., \& Hughes, J. (1991). Method: Evidence and inference-evidence and inference for ethnomethodology. In G. Button (Ed.), Ethnomethodology and the human sciences (pp. 109-136). Cambridge: Cambridge University Press.

Bjelic, D., Lynch, M. (1992). The work of a (scientific) demonstration: Respecifying Newton's and Goethe's theories of prismatic color. In G. Watson, R. M. Seiler (Eds.), Text in Context: Contributions to ethnomethodology (pp. 52-78). London: Sage.

Eberle, T. (2012). Phenomenological life-world analysis and ethnomethodology's program. Human Studies, 35, 279-304.

Ellis, W. D. (Ed.). (1938). A source book of gestalt psychology. London: Routledge and Kegan Paul.

Fele, G. (2008). The phenomenal field: Ethnomethodological perspectives on collective phenomena. Human Studies, 31(3), 299-322.

Garfinkel, H. (1963). A conception of, and experiments with, "trust" as a condition of stable concerted actions. In O. J. Harvey (Ed.), Motivation and social interaction: Cognitive approaches (pp. 187238). New York: Ronald Press. 
Garfinkel, H. (1965). Sign functions: Organized activities as methods for making an invisible world observable. Paper delivered to the social psychology section at the annual meetings of the American Sociological Associations, Chicago, IL (30 August).

Garfinkel, H. (1967). Studies in ethnomethodology. Englewood Cliffs, NJ: Prentice Hall.

Garfinkel, H. (1988). Evidence for locally produced, naturally accountable phenomena of order, logic, reason, meaning, method, etc. in and as of the essential quiddity of immortal ordinary society (I of IV): An announcement of studies. Sociological Theory, 6(1), 103-109.

Garfinkel, H. (1991). Respecification: evidence for locally produced, naturally accountable phenomena of order*, logic, reason, meaning, method, etc. in and as of the essential haecceity of immortal ordinary society (I): An announcement of studies. In G. Button (Ed.), Ethnomethodology and the Human Sciences (pp. 10-19). Cambridge, UK: Cambridge University Press.

Garfinkel, H. (2002). Ethnomethodology's program: Working out Durkheim's aphorism. A. W. Rawls (Ed.). Lanham, MD: Rowman \& Littlefield.

Garfinkel, H. (2007a). Lebenswelt origins of the sciences: Working out Durkheim's aphorism, Book Two: Workplace and documentary diversity of ethnomethodological studies of work and sciences by ethnomethodology's authors: What did we do? What did we learn? Human Studies, 30, 9-56.

Garfinkel, H. (2007b). Four relations between literatures of the social scientific movement and their specific ethnomethodological alternates. In S. Hester \& D. Francis (Eds.), Orders of ordinary action (pp. 13-33). Aldershot: Ashgate.

Garfinkel, H., \& Livingston, E. (2003). Phenomenal field properties of order in formatted queues and their neglected standing in the current situation of inquiry. Visual Studies, 18(1), 21-28.

Garfinkel, H., Lynch, M., \& Livingston, E. (1981). The work of a discovering science construed with materials from the optically discovered pulsar. Philosophy of the Social Sciences, 11(2), 131-158.

Garfinkel, H., \& Sacks, H. (1970). On formal structures of practical actions. In J. D. McKinney \& E. A. Tiryakian (Eds.), Theoretical sociology (pp. 337-366). New York, NY: Appleton-Century Crofts.

Garfinkel, H., \& Wieder, D. L. (1992). Two incommensurable, asymmetrically alternate technologies of social analysis. In G. Watson \& R. M. Seiler (Eds.), Text in context: Contributions to Ethnomethodology (pp. 175-206). London: Sage.

Grathoff, R. (1989). Introduction. In R. Grathoff (Ed.), Philosophers in exile: The correspondence of Alfred Schutz and Aron Gurwitsch, 1939-1959 (pp. xv-xxxviii). Bloomington and Indianapolis: Indiana University Press.

Gurwitsch, A. (1941). A non-egological conception of consciousness. Philosophy and Phenomenological Research, 1(3), 325-338.

Gurwitsch, A. (1964). The field of consciousness. Pittsburgh, PA: Duquesne University Press.

Gurwitsch, A. (2010). The collected works of Aron Gurwitsch (1901-1973), Volume III. The field of consciousness: Theme, thematic field, and margin. R. M. Zaner and L. Embree (Eds.). Dordrecht, New York: Springer.

Heritage, J. (1984). Garfinkel and ethnomethodology. Cambridge: Polity.

James, W. (1987). William James-writings 1902-1910. New York: Penguin.

Koffka, K. (1924). The growth of the mind. An introduction to child-psychology. R. M. Ogden (Trans.). London: Routledge \& Kegan Paul.

Liberman, K. (2013). More studies in ethnomethodology. Albany, NY: SUNY Press.

Livingston, E. (1987). Pedestrian traffic flow. In E. Livingston, Making sense of ethnomethodology (pp. 21-27). London: Routledge \& Kegan Paul.

Lynch, M. (1991a). Method: measurement ordinary and scientific measurement as ethnomethodological phenomena. In G. Button (Ed.), Ethnomethodology and the human sciences (pp. 77-108). Cambridge: Cambridge University Press.

Lynch, M. (1991b). Laboratory space and the technological complex: An investigation of topical contextures. Science in Context, 4, 51-78.

Lynch, M. (1993). Scientific practice and ordinary action: Ethnomethodology and social studies of science. New York: Cambridge University Press.

Macbeth, D. (2012). Some notes on the play of basketball in its circumstantial detail, and an introduction to their occasion. Human Studies, 35(2), 193-208.

Maynard, D. (1996). Introduction of Harold Garfinkel for the Cooley-Mead award. Social Psychology Quarterly, 59, 1-4.

Merleau-Ponty, M. (1962). Phenomenology of perception. London: Routledge and Kegan Paul.

Meyer, C. (forthcoming). Alfred Schütz, Aron Gurwitsch, Harold Garfinkel: The phenomenological origins of ethnomethodology. In A. Carlin, A. Dennis, K. N. Jenkings, O. Lindwall, M. Mair (Eds.), 
Routledge international handbook of ethnomethodology and conversation analysis. London: Routledge.

Psathas, G. (2004). Alfred Schutz's influence on American sociologists and sociology. Human Studies, $27(1), 1-35$.

Rawls, A. W. (2002). Editor's introduction. In H. Garfinkel, Ethnomethodology's program: Working out Durkheim's aphorism (pp. 1-64). Lanham, MD: Rowman and Littlefield.

Rawls, A. W., \& Turowetz, J. (2019). "Discovering culture" in interaction: Solving problems in cultural sociology by recovering the interactional side of Parsons' conception of culture. American Journal of Cultural Sociology. Online First. Published: 16 August 2019.

Vom Lehn, D. (2014). Harold Garfinkel: The creation and development of ethnomethodology. Walnut Creek, CA: Left Coast Press.

Watson, R. D. (2008). Comparative sociology, laic and analytic: Some critical remarks on comparison in conversation analysis. Cahiers de praxématique, 50, 197-238.

Wieder, D. L. (1974). Language and social reality. The case of telling the convict code. The Hague: Mouton.

Publisher's Note Springer Nature remains neutral with regard to jurisdictional claims in published maps and institutional affiliations. 